Pacific Journal of Mathematic 


\title{
SOME DUAL SERIES EQUATIONS INVOLVING LAGUERRE POLYNOMIALS
}

\author{
JOHN S. LOWNDES
}

\begin{abstract}
In this paper an exact solution is found for the dual series equations

(1) $\sum_{n=0}^{\infty} C_{n} \Gamma(\alpha+\beta+n) L_{n}(\alpha ; x)=f(x), \quad 0 \leqq x<d$,

(2) $\sum_{n=0}^{\infty} C_{n} \Gamma(\alpha+1+n) L_{n}(\alpha ; x)=g(x), \quad d<x<\infty$,

where $\alpha+\beta>0,0<\beta<1, L_{n}(\alpha ; x)=L_{n}^{\alpha}(x)$ is the Laguerre polynomial and $f(x)$ and $g(x)$ are known functions.
\end{abstract}

In a recent paper Srivastava [3] has solved the equations

$$
\begin{gathered}
\sum_{n=0}^{\infty}\left\{A_{n} / \Gamma(\alpha+1+n)\right\} L_{n}(\alpha ; x)=f(x), \quad 0 \leqq x<d, \\
\text { (4) } \sum_{n=0}^{\infty}\left\{A_{n} / \Gamma(\alpha+1 / 2+n)\right\} L_{n}(\alpha ; x)=g(x), \quad d<x<\infty, \alpha>-1 / 2,
\end{gathered}
$$

by considering separately the equations when $(a) g(x) \equiv 0,(b) \mathrm{f}(x) \equiv 0$, and reducing the problem in each case to that of solving an Abel integral equation. Srivastava's equations are a special case of (1) and (2) with $\beta=1 / 2$ and $A_{n}=\Gamma(\alpha+1+n) \Gamma(\alpha+1 / 2+n) C_{n}$.

The solution presented in this paper employs a multiplying factor technique which is more direct than the method given in [3] and is similar to that used by Noble [2] to solve some dual series equations involving Jacobi polynomials.

2. In the course of the analysis we shall use the following results.

From [1, p. 293(5), p. 405(20)] it is readily shown that

$$
\int_{0}^{y} x^{\alpha}(y-x)^{\beta-1} L_{n}(\alpha ; x) d x=\frac{\Gamma(\beta) \Gamma(\alpha+1+n)}{\Gamma(\alpha+\beta+1+n)} y^{\alpha+\beta} L_{n}(\alpha+\beta ; y),
$$

where $-1<\alpha, \beta>0$, and

$$
\int_{y}^{\infty}(x-y)^{-\beta} e^{-x} L_{n}(\alpha ; x) d x=\Gamma(1-\beta) e^{-y} L_{n}(\alpha+\beta-1 ; y),
$$

where $1>\beta, \alpha+\beta>0$.

The orthogonality relation for the Laguerre polynomials is

$$
\int_{0}^{\infty} x^{\alpha} e^{-x} L_{n}(\alpha ; x) L_{m}(\alpha ; x) d x=\frac{\Gamma(\alpha+1+n)}{\Gamma(n+1)} \delta_{m n}, \alpha>-1,
$$


where $\delta_{m n}$ is the Kronecker delta.

3. Solution of the problem. Multiplying equation (1) by $x^{\alpha}(y-x)^{\beta-1}$, equation (2) by $(x-y)^{-\beta} e^{-x}$ and integrating with respect to $x$ over $(0, y)$ and $(y, \infty)$ respectively we find on using the results (5) and (6)

(8) $\sum_{n=0}^{\infty} C_{n} \frac{\Gamma(\alpha+1+n)}{(\alpha+\beta+n)} L_{n}(\alpha+\beta ; y)=\frac{y^{-\alpha-\beta}}{\Gamma^{\prime}(\beta)} \int_{0}^{y} x^{\alpha}(y-x)^{\beta-1} f(x) d x$, where $0<y<d, \alpha>-1, \beta>0$, and

$$
\begin{aligned}
\sum_{n=0}^{\infty} C_{n} \Gamma(\alpha+1+n) L_{n}(\alpha+\beta-1 ; y) \\
=\frac{e^{y}}{\Gamma(1-\beta)} \int_{y}^{\infty}(x-y)^{-\beta} e^{-x} g(x) d x,
\end{aligned}
$$

for $d<y<\infty, 1>\beta, \alpha+\beta>0$.

If we now multiply equation (8) by $y^{\alpha+\beta}$, differentiate with respect to $y$ and use the formula

$$
\frac{d}{d x}\left\{x^{\alpha} L_{n}(\alpha ; x)\right\}=(n+\alpha) x^{\alpha-1} L_{n}(\alpha-1 ; x),
$$

we find

$$
\begin{aligned}
\sum_{n=0}^{\infty} C_{n} \Gamma(\alpha+1+n) L_{n}(\alpha+\beta-1 ; y) \\
=\frac{y^{1-\alpha-\beta}}{\Gamma(\beta)} \frac{d}{d y} \int_{0}^{y} x^{\alpha}(y-x)^{\hat{\beta}-1} f(x) d x,
\end{aligned}
$$

where $0<y<d, \beta>0, \alpha>-1$.

The left hand sides of equations (9) and (11) are now identical and using the orthogonality relation (7) we see that the solution of equations (1) and (2) for $\alpha+\beta>0,0<\beta<1$, is given by

$$
C_{n}=\frac{\Gamma(n+1)}{\Gamma(\alpha+1+n) \Gamma(\alpha+\beta+n)} B_{n}(\alpha, \beta ; d),
$$

where

$$
\begin{aligned}
& B_{n}(\alpha, \beta ; d)=\frac{1}{\Gamma(\beta)} \int_{0}^{d} e^{-y} L_{n}(\alpha+\beta-1 ; y) F(y) d y \\
& \quad+\frac{1}{\Gamma(1-\beta)} \int_{d}^{\infty} y^{\alpha+\beta-1} L_{n}(\alpha+\beta-1 ; y) G(y) d y,
\end{aligned}
$$

and

$$
F(y)=\frac{d}{d y} \int_{0}^{y} x^{\alpha}(y-x)^{\beta-1} f(x) d x,
$$




$$
G(y)=\int_{y}^{\infty}(x-y)^{-\beta} e^{-x} g(x) d x .
$$

To obtain the solution of Srivastava's equations (3) and (4) we write $\beta=1 / 2, A_{n}=\Gamma(\alpha+1+n) \Gamma(\alpha+1 / 2+n) C_{n}$ in (12) and find that

$$
\begin{aligned}
A_{n}= & \frac{\Gamma(n+1)}{\Gamma(1 / 2)}\left\{\int_{d}^{d} e^{-y} L_{n}(\alpha-1 / 2 ; y) F_{1}(y) d y\right. \\
& \left.+\int_{d}^{\infty} y^{\alpha-1 / 2} L_{n}(\alpha-1 / 2 ; y) G_{1}(y) d y\right\},
\end{aligned}
$$

for $\alpha>-1 / 2$, and where $F_{1}(y)$ and $G_{1}(y)$ are given by equations (14) and (15) respectively with $\beta=1 / 2$.

Comparing the above solution with that obtained in [3] it can be seen that they are in agreement except for the form of the function $G_{1}(y)$. The limits on the integrals of equations (4.7) and (4.8) in Srivastava's paper are wrong and should read $(x, \infty)$ and $(u, \infty)$ respectively. When these corrections have been made we find that his term corresponding to $G_{1}(y)$ can be written in the notation of the present paper as

$$
-\frac{d}{d y} \int_{y}^{\infty}(x-y)^{-1 / 2} d x \int_{x}^{\infty} e^{-u} g(u) d u
$$

After inverting the order of integration, carrying out the integration in $x$ and performing the differentiation with respect to $y$ it is found that (17) is equal to $G_{1}(y)$. Hence with this simplification Srivastava's solution reduces to that given by equation (16).

4. It is also possible without computing the coefficients $C_{n}$ to find the values of series (1) and (2) in the regions where their values are not specified. We define (1) to have the value $h(x), d<x<\infty$, and (2) to have the value $k(x), 0 \leqq x<d$.

(a) Calculation of $h(x)$. Substituting for $C_{n}$ from equation (12) into (1) and interchanging the order of integration and summation we find

$$
\begin{aligned}
h(x) & =\frac{1}{\Gamma(\beta)} \int_{0}^{d} e^{-y} F(y) S_{1}(x, y) d y \\
& +\frac{1}{\Gamma(1-\beta)} \int_{d}^{\infty} y^{\alpha+\beta-1} G(y) S_{1}(x, y) d y, \quad d<x<\infty,
\end{aligned}
$$

where

$$
S_{1}(x, y)=\sum_{n=0}^{\infty} \frac{\Gamma(n+1)}{\Gamma(\alpha+1+n)} L_{n}(\alpha ; x) L_{n}(\alpha+\beta-1 ; y) .
$$


Using the results (6) and (7) it is easily shown that

$$
S_{1}(x, y)=\frac{e^{y} x^{-\alpha}(x-y)^{-\beta}}{\Gamma(1-\beta)} H(x-y),
$$

where $H(x)$ is the Heaviside unit function.

From equations (18) and (20) we see that $h(x)$ is given by

$$
\begin{gathered}
\Gamma(1-\beta) x^{\alpha} h(x)=\frac{1}{\Gamma(\beta)} \int_{0}^{d}(x-y)^{-\beta} F(y) d y \\
\quad+\frac{1}{\Gamma(1-\beta)} \int_{d}^{x} e^{y} y^{\alpha+\beta-1}(x-y)^{-\beta} G(y) d y,
\end{gathered}
$$

for $d<x<\infty$, where $F(y)$ and $G(y)$ are given by equations (14) and (15).

(b) Calculation of $k(x)$. Using the differentiation formula

$$
e^{-x} L_{n}(\alpha ; x)=-\frac{d}{d x}\left\{e^{-x} L_{n}(\alpha-1 ; x)\right\},
$$

we may write equation (2) as

$$
\begin{gathered}
\frac{d}{d x} e^{-x} \sum_{n=0}^{\infty} C_{n} \Gamma(\alpha+1+n) L_{n}(\alpha-1 ; x) \\
=-e^{-x} k(x), \quad 0 \leqq x<d .
\end{gathered}
$$

Substituting for $C_{n}$ and interchanging the order of integration and summation we find

$$
\begin{gathered}
e^{-x} k(x)=-\frac{d}{d x} e^{-x}\left\{\frac{1}{\Gamma(\beta)} \int_{0}^{d} e^{-y} F(y) S_{2}(x, y) d y\right. \\
\left.+\frac{1}{\Gamma(1-\beta)} \int_{d}^{\infty} y^{\alpha+\beta-1} G(y) S_{2}(x, y) d y\right\},
\end{gathered}
$$

for $0 \leqq x<d$, and

$$
\begin{gathered}
S_{2}(x, y)=\sum_{n-0}^{\infty} \frac{\Gamma(n+1)}{\Gamma(\alpha+\beta+n)} L_{n}(\alpha-1 ; x) L_{n}(\alpha+\beta-1 ; y) \\
=\frac{1}{\Gamma(\beta)} e^{x}(y-x)^{\beta-1} y^{1-\alpha-\beta} H(y-x),
\end{gathered}
$$

where the series has been summed using the results (6) and (7).

Substituting for $S_{2}(x, y)$ in (24) we see that $k(x)$ is given by

$$
\begin{aligned}
\Gamma(\beta) e^{-x} k(x) & =-\frac{d}{d x}\left\{\frac{1}{\Gamma(\beta)} \int_{x}^{d} e^{-y}(y-x)^{\beta-1} y^{1-\alpha-\beta} F(y) d y\right. \\
& \left.+\frac{1}{\Gamma(1-\beta)} \int_{d}^{\infty}(y-x)^{\beta-1} G(y) d y\right\},
\end{aligned}
$$


when $0 \leqq x<d$.

It is perhaps interesting to note that the expressions for the functions $k(x)$ and $h(x)$ do not involve Laguerre polynomials.

\section{REFERENCES}

1. A. Erdélyi et al., Tables of Integral Transforms, Vol. 2, McGraw-Hill, 1954.

2. B. Noble, Some dual series equations involving Jacobi polynomials, Proc. Camb. Phil. Soc. 59 (1963), 363-372.

3. K. N. Srivastava, On dual series relations involving Laguerre polynomials, Pacific J. Math. 19 (1966), 529-533.

Received April 14, 1967.

UNIVERSITY OF STRATHCLYDE

GLASGOW, SCOTLAND 



\section{PACIFIC JOURNAL OF MATHEMATICS}

\section{EDITORS}

H. ROYDEN

Stanford University

Stanford, California

\section{J. P. Jans}

University of Washington

Seattle, Washington 98105

\section{J. DUGUNDJI}

Department of Mathematics University of Southern California Los Angeles, California 90007

\section{RICHARD ARENS}

University of California

Los Angeles, California 90024

\section{ASSOCIATE EDITORS}

E. F. BECKENBACH

B. H. NEUManN

F. WOLF

K. YosIDA

\section{SUPPORTING INSTITUTIONS}

UNIVERSITY OF BRITISH COLUMBIA CALIFORNIA INSTITUTE OF TECHNOLOGY UNIVERSITY OF CALIFORNIA MONTANA STATE UNIVERSITY UNIVERSITY OF NEVADA NEW MEXICO STATE UNIVERSITY OREGON STATE UNIVERSITY UNIVERSITY OF OREGON OSAKA UNIVERSITY UNIVERSITY OF SOUTHERN CALIFORNIA
STANFORD UNIVERSITY

UNIVERSITY OF TOKYO UNIVERSITY OF UTAH WASHINGTON STATE UNIVERSITY UNIVERSITY OF WASHINGTON AMERICAN MATHEMATICAL SOCIETY CHEVRON RESEARCH CORPORATION TRW SYSTEMS NAVAL WEAPONS CENTER 


\section{Pacific Journal of Mathematics}

\section{Vol. 25, No. $1 \quad$ September, 1968}

Glen Eugene Bredon, Cosheaves and homology................... 1

Robin Ward Chaney, A chain rule for the transformation of integrals in

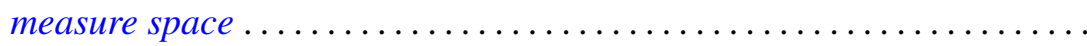

Colin W. Clark, On relatively bounded perturbations of ordinary differential operators................................... 59

John Edwin Diem, A radical for lattice-ordered rings.............. 71

Zeev Ditzian, On a class of convolution transforms ................ 83

Dennis Garoutte and Paul Adrian Nickel, A note on extremal properties characterizing weakly $\lambda$-valent principal functions............. 109

Shwu-Yeng Tzeng Lin, Fixed point properties and inverse limit spaces . . . 117

John S. Lowndes, Some dual series equations involving Laguerre polynomials ................................. 123

Kirti K. Oberai, Sum and product of commuting spectral operators ....... 129

J. N. Pandey and Armen H. Zemanian, Complex inversion for the generalized convolution transformation..................... 147

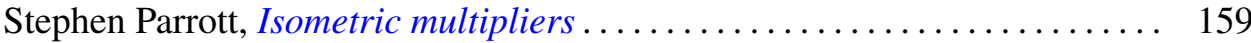

Manoranjan Prasad, Note on an extreme form .................. 167

Maciej Skwarczyński, A representation of a bounded function as infinite product in a domain with Bergman-Shilov boundary surface ......... 177

John C. Taylor, The Šilov boundary for a lattice-ordered semigroup ...... 185 Donald Reginald Traylor and James Newton Younglove, On normality and pointwise paracompactness ............................. 193

L. Tzafriri, Quasi-similarity for spectral operators on Banach spaces ... 